\title{
Forebrain-Specific CRF Overproduction During Development is Sufficient to Induce Enduring Anxiety and Startle Abnormalities in Adult Mice
}

\author{
Mate Toth ${ }^{1,2,8}$, Jodi E Gresack ${ }^{1,3,8}$, Debra A Bangasser ${ }^{4,5}$, Zach Plona ${ }^{4}$, Rita J Valentino ${ }^{4}$, \\ Elizabeth I Flandreau', Isabelle M Mansuy ${ }^{6}$, Emilio Merlo-Pich ${ }^{7}$, Mark A Geyer ${ }^{1,2}$ and \\ Victoria B Risbrough*,1,2
}

'Department of Psychiatry, University of California San Diego, La Jolla, CA, USA; ${ }^{2}$ Center of Excellence for Stress and Mental Health, Veterans Affairs Hospital, La Jolla, CA, USA; ${ }^{3}$ Laboratory of Molecular and Cellular Neuroscience, The Rockefeller University, New York, NY, USA;

${ }^{4}$ Department of Anesthesiology and Critical Care Medicine, Children's Hospital of Philadelphia, Philadelphia, PA, USA; ${ }^{5}$ Department of Psychology and Neuroscience Program, Temple University, Philadelphia, PA, USA; ${ }^{6}$ Brain Research Institute, University and ETH Zürich, Zürich, Switzerland;

${ }^{7}$ Neuroscience Disease Therapeutic Area, Pharmaceutical Division, F. Hoffman — La Roche, Basel, Switzerland

\begin{abstract}
Corticotropin releasing factor (CRF) regulates physiological and behavioral responses to stress. Trauma in early life or adulthood is associated with increased CRF in the cerebrospinal fluid and heightened anxiety. Genetic variance in CRF receptors is linked to altered risk for stress disorders. Thus, both heritable differences and environmentally induced changes in CRF neurotransmission across the lifespan may modulate anxiety traits. To test the hypothesis that CRF hypersignaling is sufficient to modify anxiety-related phenotypes (avoidance, startle, and conditioned fear), we induced transient forebrain-specific overexpression of CRF (CRFOE) in mice (I) during development to model early-life stress, (2) in adulthood to model adult-onset stress, or (3) across the entire postnatal lifespan to model heritable increases in CRF signaling. The consequences of these manipulations on CRF peptide levels and behavioral responses were examined in adulthood. We found that transient CRFOE during development decreased startle habituation and prepulse inhibition, and increased avoidance (particularly in females) recapitulating the behavioral effects of lifetime CRFOE despite lower CRF peptide levels at testing. In contrast, CRFOE limited to adulthood reduced contextual fear learning in females and increased startle reactivity in males but did not change avoidance or startle plasticity. These findings suggest that forebrain CRFOE limited to development is sufficient to induce enduring alterations in startle plasticity and anxiety, while forebrain CRFOE during adulthood results in a different phenotype profile. These findings suggest that startle circuits are particularly sensitive to forebrain CRFOE, and that the impact of CRFOE may be dependent on the time of exposure.
\end{abstract}

Neuropsychopharmacology (2014) 39, I409-1419; doi:10.1038/npp.2013.336; published online 5 February 2014

Keywords: CRF overexpression; anxiety; startle; development; sex differences

\section{INTRODUCTION}

Corticotropin releasing factor (CRF) coordinates autonomic, endocrine, and behavioral responses to stress. Both acute activation and overexpression of CRF (CRFOE) across the lifetime increase anxiety-like responses while pharmacological blockade or genetic disruption of CRF receptor type 1 (CRFR1) results in decreased anxiety (Risbrough and Stein, 2006b; Stenzel-Poore et al, 1994; Timpl et al, 1998; Zorrilla and Koob, 2010). CRF signaling in the forebrain is necessary for many CRF- and stress-induced anxiety-like

*Correspondence: Dr Victoria Risbrough, Department of Psychiatry, University of California San Diego, 9500 Gilman Drive MC0804, La Jolla CA 92093-0804, USA, Tel: + I 16195433582, Fax: + I 16195432475, E-mail: vrisbrough@ucsd.edu

${ }^{8}$ These authors contributed equally to this work.

Received 29 July 2013; revised 23 October 2013; accepted 16 November 2013; accepted article preview online II December 2013 behaviors (Kolber et al, 2010; Muller et al, 2003). In addition, early stress exposure in animals induces long-term changes in the CRF system (Plotsky et al, 2005). CRF concentrations are elevated in the cerebrospinal fluid of individuals with childhood trauma history and posttraumatic stress disorder (PTSD) (Baker et al, 1999; Bremner et al, 1997; Lee et al, 2005), while CRFR1 gene polymorphisms modulate the outcome of traumatic events (Bradley et al, 2008). However, these association studies explain neither the causal relationships nor the underlying mechanisms between CRF signaling and anxiety. Traumatic experience may induce long-term enhancement of CRF neurotransmission resulting in increased anxiety, but it is also possible that individuals with trait differences in CRF signaling are more susceptible to develop anxiety disorders. CRF hypersignaling during early-life stress is another possible trajectory to develop increased risk for anxiety in adulthood. Animal studies suggest that CRF hypersignaling 
produces biomarkers that mimic some of those described in anxiety disorders, including increased startle reactivity, reduced startle plasticity, altered HPA-axis sensitivity, and altered structure and activity of the hippocampus and the amygdala supporting the potential role of CRF in increased anxiety (Ivy et al, 2010; Rainnie et al, 2004; Risbrough and Stein, 2006b).

In the present study, we induced CRFOE in a temporally controlled manner to compare the contribution of different time points of CRF hypersignaling in the genesis of phenotypes associated with anxiety disorders. To model the hypotheses described above, we induced transient CRFOE in the forebrain during development $\left(\mathrm{CRFOE}_{\mathrm{dev}}\right)$, adulthood $\left(\mathrm{CRFOE}_{\text {adult }}\right)$ or along the whole postnatal lifespan $\left(\mathrm{CRFOE}_{\text {life }}\right)$. $\mathrm{CRFOE}_{\mathrm{dev}}$ aimed to model CRF hypersignaling during childhood (early-life stress; (Heim and Nemeroff, 2001; Lee et al, 2005)), CRFOE life $_{\text {modeled }}$ lifelong CRF hypersignaling (genetic predispositions; (Bradley et al, 2008)), and CRFOE adult modeled adult-onset CRF hypersignaling (eg, induced by traumatic stress in adulthood; (Baker et al, 1999; Bremner et al, 1997)). The anatomical targeting of CRFOE was restricted to the forebrain in order to exclude direct HPA-axis changes. Commonly described symptom domains in anxiety disorders include avoidance, altered fear learning, and startle hyperreactivity. Thus the aim of this model comparison is to help elucidate what 'symptom domains' forebrain CRF hypersignaling is sufficient to produce and what time periods are sufficient for these changes, providing a better understanding of phenotypes that are most suited to modulation of CRF systems for treatment (Zorrilla and Koob, 2010). Finally, since women exhibit higher risk for stress-related anxiety disorders and preclinical evidence has shown significant sex biases in CRF signaling (Bangasser et al, 2013; Kessler et al, 1993; Weathington and Cooke, 2012), we examined all behaviors in both males and females with comparative analysis between sexes.

\section{MATERIALS AND METHODS}

\section{Generation of Mice with Inducible Forebrain-Specific CRF Overexpression}

To achieve temporal control of CRF expression in the forebrain, we crossed two genetically modified mouse lines (backcrossed on C57BL/6J background to $\mathrm{N}>8$ generations) carrying a CaMKII $\alpha$ promoter-driven rtTA2 transgene (Michalon et al, 2005) and a doxycycline-regulated tetO promoter fused to the CRF gene (Vicentini et al, 2009) to produce double mutant mice. Genotyping was carried out by quantitative polymerase chain reaction (Transnetyx, Memphis Tennessee, USA). CRFOE was induced by doxycycline (DOX) administration in either breeder chow for the dams (before weaning) or common mouse chow (after weaning) (Harlan Laboratories, Indianapolis, IN) in $6 \mathrm{mg} \mathrm{DOX} / \mathrm{g}$ dose which corresponds to $3.5 \mathrm{mg} \mathrm{DOX} / \mathrm{g}$ body weight/day. This dose was shown to induce a neuronspecific expression of different reporter genes in the forebrain with detectable levels after 4 days and reaching its maximum level after a week, and is able to induce CRFOE in the developing brain as early as P0 (Michalon et al, 2005). DOX treatment was applied between postnatal day 2 (PD2) and PD23 (ie, prepubertal period) to induce $\mathrm{CRFOE}_{\mathrm{dev}}(n=11-16$ per group), from PD2 to the end of testing to induce $\mathrm{CRFOE}_{\text {life }}(n=7-12$ per group), and from PD69 to the end of testing to induce CRFOE adult $(n=18-21$ per group). Testing started from PD90. After confirming that DOX alone did not affect behavioral outcomes in wildtype animals (Supplementary Table S1), double mutant littermates without DOX treatment were used as control subjects in all experiments.

\section{Housing Conditions}

Mice were housed 3-4/cage after weaning (PD28) in a temperature-controlled $\left(21-22^{\circ} \mathrm{C}\right)$ room under a reverse $12 \mathrm{~h}$ light/dark cycle (lights off at 0800 hours). All testing occurred from 1000 hours to 1400 hours and was conducted in accordance with the Principles of Laboratory Animal Care, National Institutes of Health guidelines, as approved by the University of California, San Diego Animal Care Committees.

\section{Histological Verification of CRFOE}

Immunohistochemistry. To characterize peptide levels at behavioral testing onset, a separate subset of $\mathrm{CRFOE}_{\mathrm{dev}}$, $\mathrm{CRFOE}_{\text {life }}$, and $\mathrm{CRFOE}_{\text {adult }}$ mice $(N=5-6$ per group) at PD90 were perfused and coronal brain sections were labeled for CRF using anti-CRF antibody $(1: 2000$, Dr Wylie Vale, the Salk Institute, La Jolla, CA). See Supplementary Material for additional information.

In situ hybridization. To characterize the qualitative distribution of CRFOE during development, we assessed CRF RNA levels in separate subset of mice after 5, 12, and 21 days of DOX treatment and 2 weeks after cessation of DOX treatment (PD7, PD14, PD23, and PD37, respectively). In situ hybridization was performed using ${ }^{35} \mathrm{~S}$-UTP labeled riboprobes and analyzed as previously described (Flandreau et al, 2012). See Supplementary Material for additional information.

\section{Blood Sampling and Corticosterone Assay}

Blood samples were collected from a subset of mice $(N=$ 5-15 per groups) between 7 and 10 am to assess baseline 'waking' corticosterone (CORT) levels in adulthood. Plasma corticosterone concentrations were measured by radioimmunoassay (MP Biomedicals, Solon, OH, USA). See Supplementary Material for additional information.

\section{Experimental Design}

Behavioral testing started at PD90 in the following order: locomotor/exploratory activity; conditioned fear; startle reactivity; and light/dark box with at least one week between tests. In all experiments, animals were placed in or adjacent to the testing room for habituation at least $1 \mathrm{~h}$ before testing.

\section{Locomotor and Exploratory Activity Assessment}

Locomotion and investigatory behavior were measured via photo-beam system in darkened activity chambers as previously described (San Diego Instruments, San Diego, CA, USA; (Risbrough et al, 2006a)). Total distance moved 
(meters), rears, and hole pokes were recorded for $30 \mathrm{~min}$. See Supplementary Material for additional information.

\section{Conditioned Fear Test}

Fear conditioning was assessed via an automatic photobeam procedure as previously described (Gresack et al, 2010). Briefly, fear conditioning was induced by presentation of a tone (conditioned stimulus, CS: $75 \mathrm{~dB}, 4 \mathrm{kHz}$ ) for $20 \mathrm{~s}$ that co-terminated with a scrambled foot shock (unconditioned stimulus, US: $1 \mathrm{~s}, 0.5 \mathrm{~mA}$ ). Three toneshock pairings were presented with an inter-trial interval of $40 \mathrm{~s}$. Twenty-four hours later, subjects were re-exposed to the conditioning chamber and their freezing response was measured for 5 min during which time no shocks or tones were presented (context-dependent fear). Twenty-four hours afterwards mice were exposed again to the chambers with altered context across several dimensions (tactile, odor, visual) to minimize contextual cues and measure tone cue-induced fear. After a $5 \mathrm{~min}$ acclimation period, during which time no tones were presented ('pre-tone'), 12 tones were presented with an inter-trial interval of $5 \mathrm{~s}$. See Supplementary Material for additional information.

\section{Acoustic Startle}

The procedure used here was adapted from previous studies (Risbrough et al, 2004) using startle chambers (San Diego Instruments) to test multiple domains of startle reactivity: baseline startle magnitude, prepulse inhibition (PPI), and habituation of startle.

Briefly, the acoustic startle sessions included four blocks. Sessions began with a 5-min acclimation period followed by delivery of five each of $120 \mathrm{~dB}$ startle pulses (Block1). Then a second block tested startle responses for different intensities $(80,90,100,110$, and $120 \mathrm{~dB})$. The third block tested PPI of $120 \mathrm{~dB}$ startle pulses using three different prepulse intensities $(68,71$, and $77 \mathrm{~dB})$. The last block included five pulses of $120 \mathrm{~dB}$ to assess startle habituation (\% Reduction of Startle Magnitude $=$ Startle Magnitude (Block1) - Startle Magnitude (Block4)). In all experiments, the average startle magnitude over the record window (65 milliseconds) was used for all data analysis. See Supplementary Material for additional information.

\section{Light/Dark Box Test}

The light/dark box (LD box) consisted of two $18 \times 20 \times 18$ $\mathrm{cm}$ chambers joined by a $6 \times 6 \mathrm{~cm}$ door. One side was well lit (850 lux) and the other was unlit/covered ( $<5$ lux). Mice were placed in the light chamber at the start of the test and their activity was recorded for $5 \mathrm{~min}$. Time spent in the dark chamber and number of entries into the light chamber were analyzed by Ethovision Tracking Software (Noldus, Leesburg, VA, USA).

\section{Statistical Analysis and Data Visualization}

All quantitative variables were analyzed by two-way ANOVA tests using Systat software (Systat, Chicago, IL, USA). Differences were considered significant and marginal if $p<0.05$ and $p<0.10$, respectively; higher $p$ values are indicated as nonsignificant (ns). An effect of sex or interaction between sex and CRFOE was consistently present across tests, thus comparisons within each sex were completed for each test. When appropriate, post hoc comparisons were also conducted. Individuals were considered outliers and excluded from the analysis for a given task if they were out of the average $\pm 2.5 \mathrm{SD}$ range, resulting in exclusion of: one male and one female control (no-DOX) subject from startle data analysis of $\mathrm{CRFOE}_{\text {life }}$ cohort; one male control (no-DOX) subject from startle data analysis of $\mathrm{CRFOE}_{\text {adult }}$ cohort; and one female $\mathrm{CRFOE}_{\text {life }}$ (DOX-on) subject from LD box analysis.

\section{RESULTS}

\section{Spatio-Temporal Overexpression of CRF}

In situ hybridization showed robust CRFOE in forebrain regions that is largely reflective of expected CAMK2a expression patterns (Allen Mouse Brain Atlas, http:// mouse.brain-map.org/). Starting at PD14 and continuing to $\mathrm{PD} 23$, robust overexpression was detected in cortex, hippocampus, and striatum while limited in the hypothalamus. This overexpression was markedly reduced 14 days after the termination of DOX treatment (PD37) (Figure 1b).

Figure 1a and Table 1 show representative photomicrographs and summarize comparative CRF peptide levels in different brain regions across CRFOE groups at PD90. Double mutant mice without DOX treatment showed similar CRF immunoreactivity (ir) compared to C57BL/6J wild-type mice. Double mutants that had CRFOE in adulthood $\left(\mathrm{CRFOE}_{\text {life }}\right.$ and $\left.\mathrm{CRFOE}_{\text {adult }}\right)$ showed different patterns of CRF-ir compared to $\mathrm{CRFOE}_{\mathrm{dev}}$ at the time of behavioral testing (PD90). In general, CRFOE in adulthood resulted in robust CRF-ir in basal ganglia-related structures (ie, striatum, ventral pallidum, and substantia nigra) with somewhat less dense CRF-ir in $\mathrm{CRFOE}_{\text {adult }}$ than $\mathrm{CRFOE}_{\text {life }}$ mice. $\mathrm{CRFOE}_{\text {life }}$ mice exhibited prominent labeling in the hippocampus, lateral septum, and area surrounding the locus coeruleus (peri-LC) that was less apparent in $\mathrm{CRFOE}_{\text {adult }}$ mice. In contrast, in $\mathrm{CRFOE}_{\mathrm{dev}}$ mice there was a notable absence of CRF-ir in most of the basal gangliarelated regions. Rather, these mice exhibited dense CRF-ir in the extended amygdala that was not seen in $\mathrm{CRFOE}_{\text {adult }}$

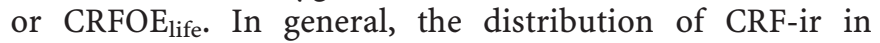
$\mathrm{CRFOE}_{\mathrm{dev}}$ mice was similar to control mice without DOX treatment but CRF-ir was more intense, whereas the actual pattern of CRF-ir differed in $\mathrm{CRFOE}_{\text {adult }}$ and $\mathrm{CRFOE}_{\text {life }}$ compared to $\mathrm{CRFOE}_{\mathrm{dev}}$ and controls. However, in situ hybridization in $\mathrm{CRFOE}_{\mathrm{dev}}$ mice during CRFOE-induction period showed an overexpression profile resembling the distribution found in CRFOE $\mathrm{adult}_{\text {and }}$ aRFOE $\mathrm{C}_{\text {life }}$ groups (ie, in striatum and hippocampus). None of the CRFOE groups exhibited increased CRF-ir in the paraventricular nucleus of the hypothalamus. Of note, $\mathrm{CRFOE}_{\mathrm{dev}}$ mice exhibited a similar CRF-ir pattern to metallothionein promoter-driven CRFOE mice except the marked hypothalamic CRF-ir in the latter (Figure 1a, Table 1; (Stenzel-Poore et al, 1994)).

\section{Weight and Corticosterone Levels}

$\mathrm{CRFOE}_{\text {life }}$ increased the body weight of female mice compared to controls, $\mathrm{CRFOE}_{\mathrm{dev}}$ and $\mathrm{CRFOE}_{\text {adult }}$ female 
a
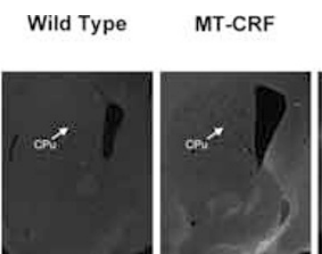

No Dox
Control

CRFOE $_{\text {adult }} \quad$ CRFOE $_{\text {life }}$

Bregma 1.18
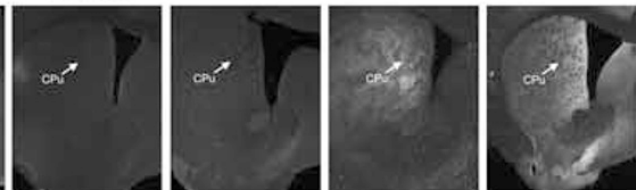

Bregma .38
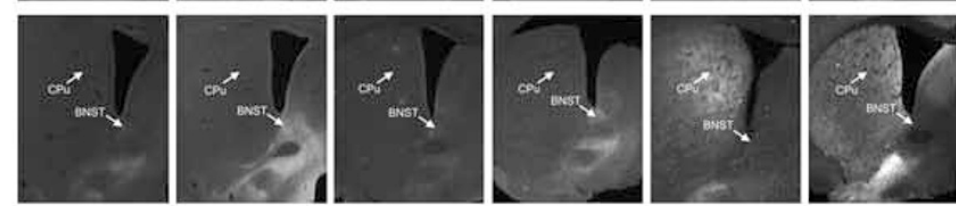

Bregma .14
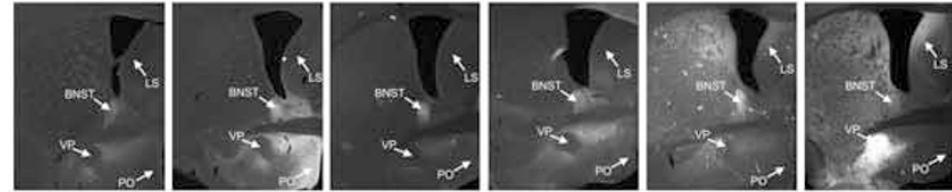

Bregma -.82
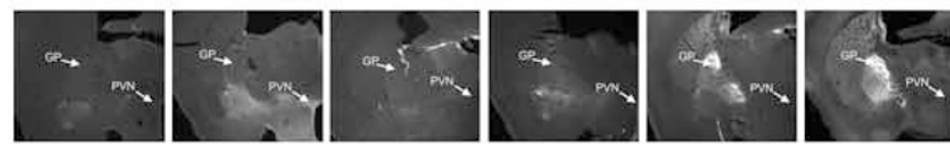

Bregma -1.22
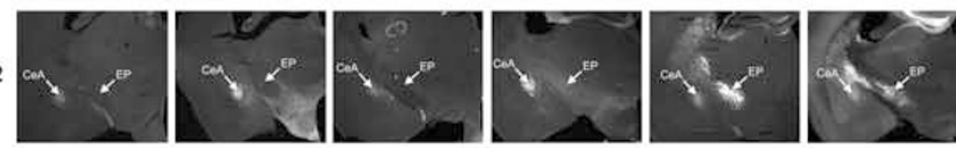

Bregma -1.94
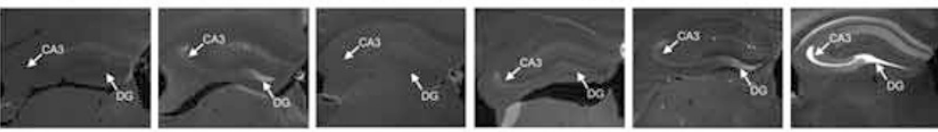

Bregma -3.52
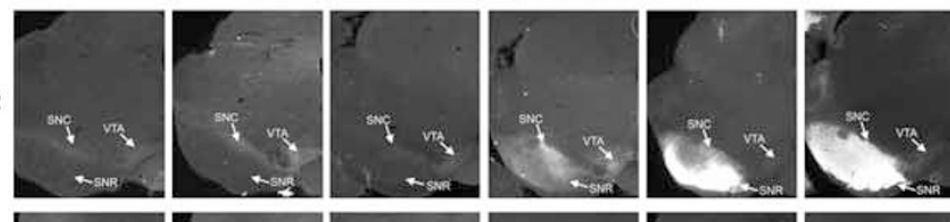

Bregma -4.36
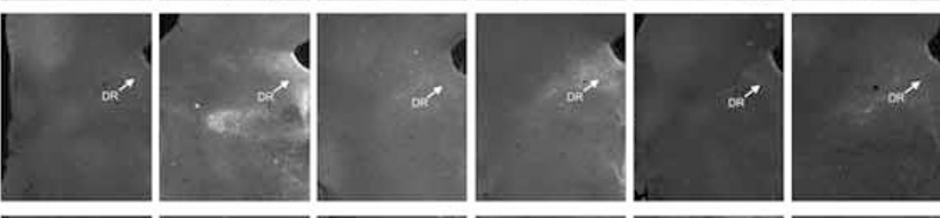

Bregma -5.40
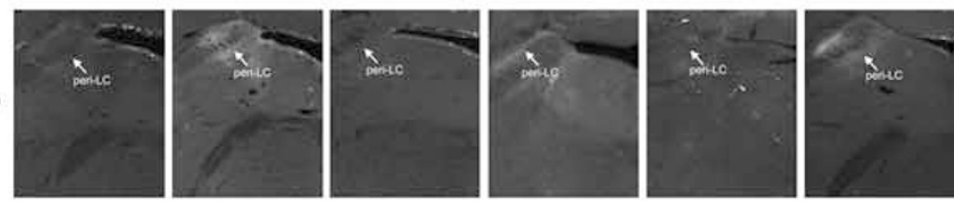

b

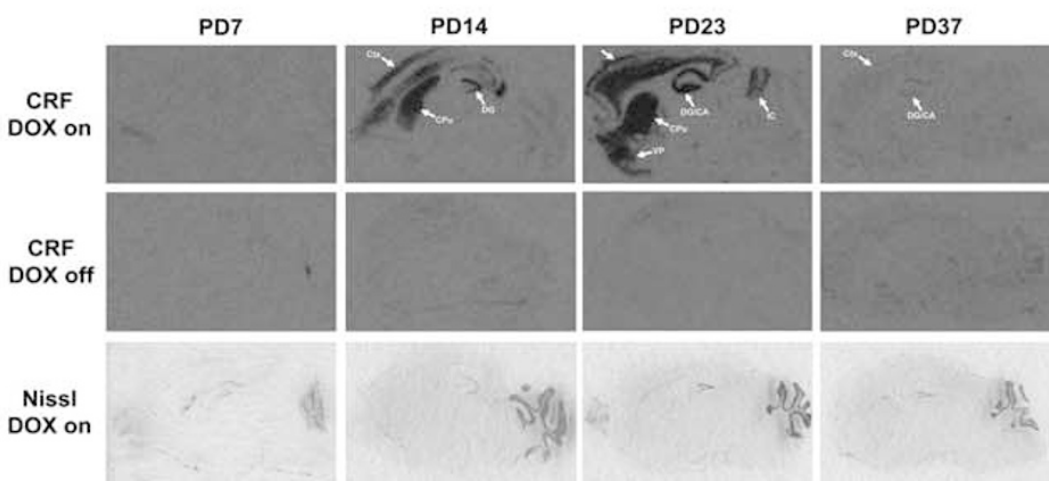


groups $(p<0.001$; Supplementary Table S2). None of the other CRFOE groups showed a change in body weight compared to control subjects.

Females showed higher resting plasma corticosterone concentrations compared to males in all groups $\left(\mathrm{F}_{\text {sex }}(1,20)>4.22,0.002<p<0.053\right)$. None of the CRFOE groups showed differences in CORT concentrations compared to controls $\left(\mathrm{F}_{\text {crfoe }}(1,35)<1.52\right.$, ns; Supplementary Table $\left.\mathrm{S} 2\right)$.

\section{Locomotor and Exploratory Activity}

Supplementary Table S3 summarizes the activity changes following different CRFOE exposure periods. In females, horizontal locomotor activity was marginally increased in $\mathrm{CRFOE}_{\mathrm{dev}}$ and $\mathrm{CRFOE}_{\text {adult }}$ groups $\left(\mathrm{F}_{\text {crfoe }}(1,24)=3.55\right.$, $p=0.072 ; \mathrm{F}_{\text {crfoe }}(1,38)=3.06, p=0.088$; respectively) but not following CRFOE $\mathrm{Clf}_{\text {life }}$ exposure $\left(\mathrm{F}_{\text {crfoe }}(1,14)=1.31\right.$, ns). Vertical activity indexed by the number of rears was unaffected by CRFOE at any time point $\left(\mathrm{F}_{\text {crfoe }}<1, \mathrm{~ns}\right)$. Exploratory activity as measured by hole poking behavior was marginally decreased in CRFOE $_{\text {adult }}$ female mice $\left(\mathrm{F}_{\text {crfoe }}(1,38)=3.42\right.$, $p=0.072)$ without any change in $\mathrm{CRFOE}_{\mathrm{dev}}$ and $\mathrm{CRFOE}_{\text {life }}$ groups $\left(\mathrm{F}_{\mathrm{crfoe}}<1, \mathrm{~ns}\right)$. In males, locomotion and exploratory activity were not altered in any $\mathrm{CRFOE}$ exposure groups $(\mathrm{F}<2.81$; ns) except a slight tendency for decreased horizontal activity following $\mathrm{CRFOE}_{\text {life }}(\mathrm{F}(1,25)=2.98 ; p=0.097)$.

\section{Conditioned Fear Test}

Acquisition of conditioned fear was similar across all CRFOE groups $\left(\mathrm{F}_{\text {time }}>7.09, p<0.001 ; \mathrm{F}_{\text {crfoe }}<1\right.$, ns). Contextual fear tested $24 \mathrm{~h}$ later did not reveal any effect of $\mathrm{CRFOE}_{\mathrm{dev}}$ $\left(\mathrm{F}_{\text {crfoe }}(1,50)<1, \mathrm{~ns}\right)$ or $\mathrm{CRFOE}_{\text {life }}\left(\mathrm{F}_{\text {crfoe }}(1,39)<1, \mathrm{~ns}\right)$. $\mathrm{CRFOE}_{\text {adult }}$ females, however, showed a strong tendency for reduced freezing compared to controls $\left(\mathrm{F}_{\text {crfoe }}(1,16)=4.42\right.$, $p=0.052)$. This effect was not found in males $\left(\mathrm{F}_{\text {crfoe }}(1,16)<1\right.$, ns) (Supplementary Figure $\left.\mathrm{S} 1\right)$. Freezing $24 \mathrm{~h}$ later in an altered context (ie, 'pre-tone' freezing) was markedly lower with similar levels across controls and CRFOE groups $\left(\mathrm{F}_{\text {crfoe }}<2.46, p>0.125\right)$ with the exception of reduced freezing in female $\mathrm{CRFOE}_{\text {life }}$ mice $\left(\mathrm{F}_{\text {crfoe }}(1,13)=10.47, p=0.007\right)$. Tone cue-induced freezing

Table I Qualitative Comparison of CRF Immunoreactivity in Regions Throughout the Brain

\begin{tabular}{|c|c|c|c|c|c|c|c|}
\hline Brain division & Region & Wild type & MT-CRF & No DOX control & CRFOE $_{\mathrm{dev}}$ & CRFOE $_{\text {adult }}$ & CRFOE $_{\text {life }}$ \\
\hline \multirow[t]{4}{*}{ Basal ganglia } & Caudate & - & - & - & - & ++ & ++ \\
\hline & Ventral pallidum & - & - & - & - & + & +++ \\
\hline & Globus pallidus & - & - & - & - & ++ & ++ \\
\hline & Entopeduncular & - & - & - & + & ++ & ++ \\
\hline Septum & Lateral septum & - & - & - & - & + & ++ \\
\hline \multirow[t]{2}{*}{ Hypothalamus } & Preoptic nuclei & - & ++ & - & + & - & - \\
\hline & Paraventricular nucleus & + & ++ & + & + & + & + \\
\hline \multirow[t]{2}{*}{ Extended amygdala } & BNST & + & +++ & + & +++ & + & + \\
\hline & Central nucleus & + & ++ & + & ++ & + & + \\
\hline \multirow[t]{3}{*}{ Hippocampus } & CAI & - & - & - & - & - & ++ \\
\hline & CA3 & - & + & - & + & ++ & +++ \\
\hline & Dentate gyrus & - & + & - & + & ++ & +++ \\
\hline \multirow[t]{4}{*}{ Midbrain } & Substantia nigra, reticular part & - & - & - & ++ & +++ & +++ \\
\hline & Substantia nigra, compact part & + & ++ & + & ++ & ++ & +++ \\
\hline & VTA & + & ++ & + & ++ & + & + \\
\hline & Dorsal raphe & + & ++ & + & ++ & + & + \\
\hline Pons & Peri-LC & + & ++ & + & ++ & + & ++ \\
\hline
\end{tabular}

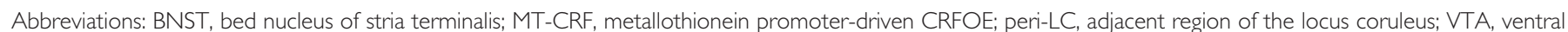
tegmental area; $(-)$, no immunoreactivity; $(+)$, low immunoreactivity; $(++)$, moderate immunoreactivity; $(+++)$, high immunoreactivity.

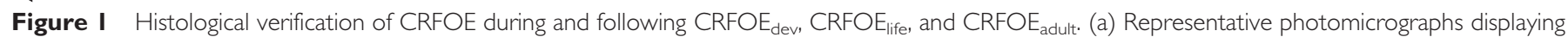

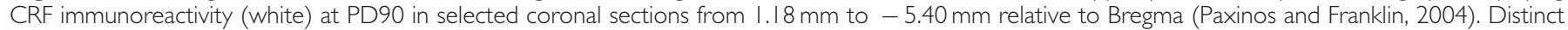

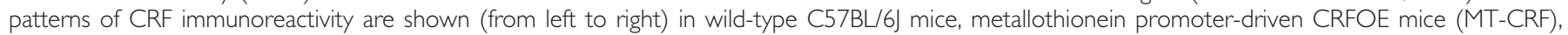

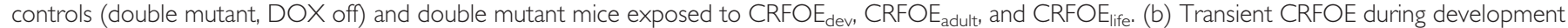

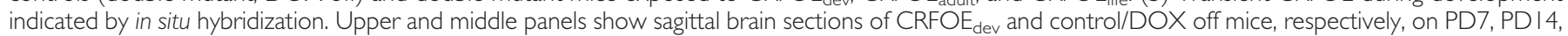

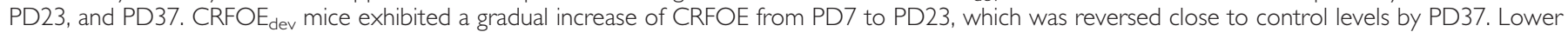

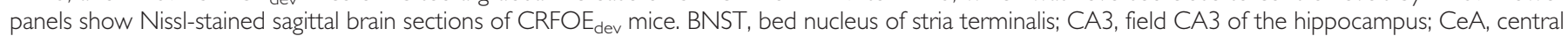

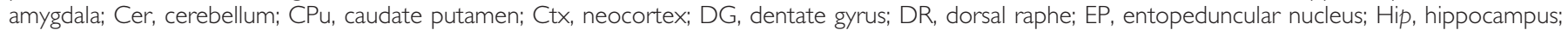

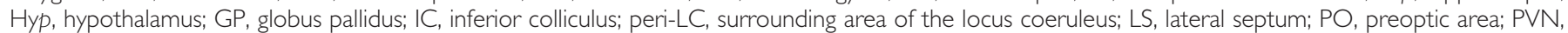

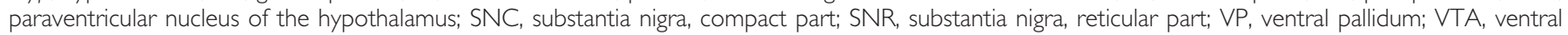
tegmental area. 
a

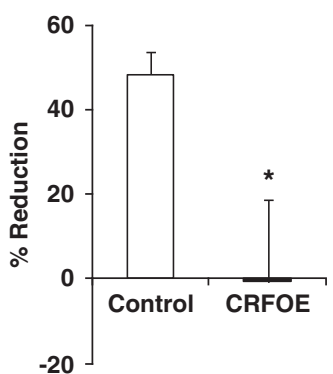

Males

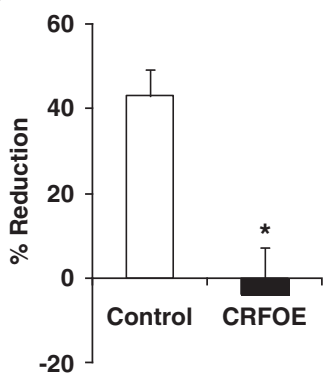

b

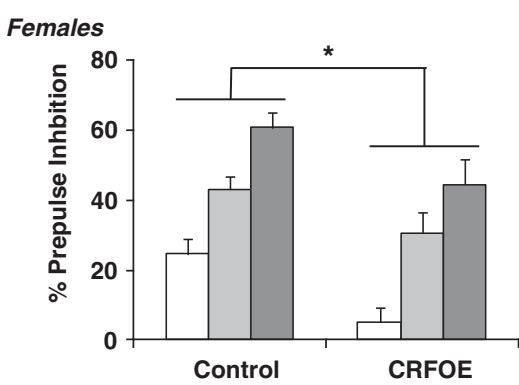

Males

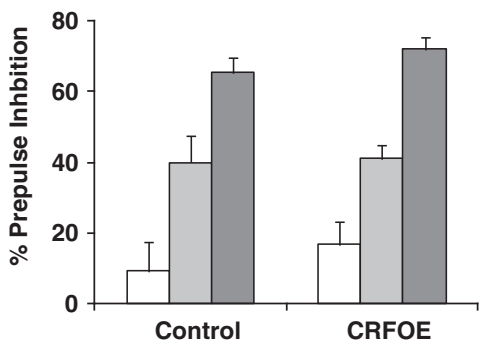

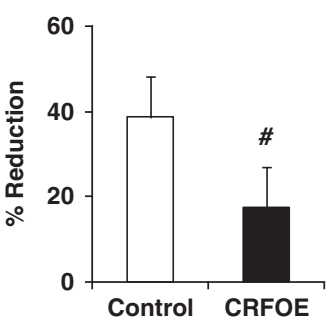

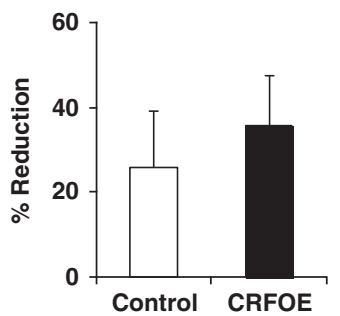

CRFOE $_{\text {adult }}$
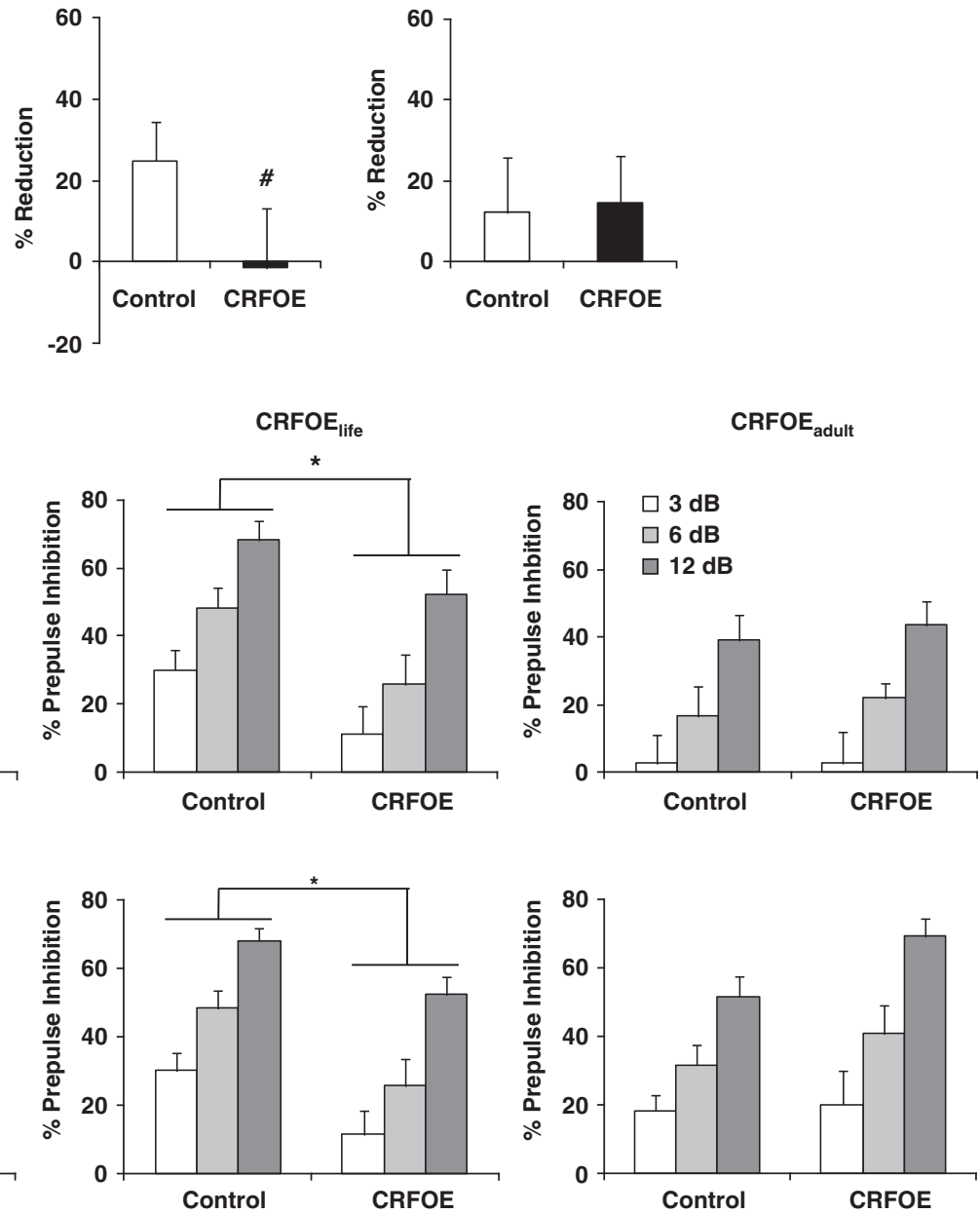

Figure 2 Changes of startle plasticity and sensorimotor gating. (a) Habituation of the startle response following CRFOE $E_{\text {dev }}, C$ CRFOElife, and CRFOE $E_{a d u l t}$ Startle habituation was markedly diminished in both sexes following CRFOE dev $_{\text {. Male and female }}$ CRFOE $_{\text {life }}$ mice showed a similar trend, which was absent in CRFOE $E_{\text {adult }}$ mice. (b) Prepulse inhibition of the startle response following $C R F O E_{\text {dev }}, C R F O E_{\text {life, }}$ and $C R F O E_{\text {adult. }}$ CRFOE $E_{\text {dev }}$ significantly reduced PPI in female mice whereas CRFOE $E_{\text {life }}$ reduced PPI in both sexes with a more pronounced effect in males. In contrast, CRFOE $E_{a d u l t}$ had no effect on PPI. * $p<0.05$, ${ }^{\#} p<0.10$ compared to same-sex control. Data are presented as mean \pm SEM.

was not changed by CRFOE (absolute freezing levels: $\mathrm{F}_{\text {crfoe }}<1$, ns; elevation from pre-tone baseline: $\mathrm{F}_{\text {crfoe }}<1.41$, ns) (Supplementary Figure S1).

\section{Acoustic Startle Response}

CRFOE significantly reduced startle plasticity in $\mathrm{CRFOE}_{\mathrm{dev}}$ and $\mathrm{CRFOE}_{\text {life }}$ mice. Although startle magnitude was un- affected by $\mathrm{CRFOE}_{\text {dev }}$ or $\mathrm{CRFOE}_{\text {life }}$ (Supplementary Figure S2), habituation of the startle response was strongly reduced in $\operatorname{CRFOE}_{\text {dev }}$ mice $\left(\mathrm{F}_{\text {crfoe }}(1,50)=20.58, p<0.001\right)$ and marginally reduced in $\mathrm{CRFOE}_{\text {life }}$ mice $\left(\mathrm{F}_{\text {crfoe }}(1,39)=3.06, p=0.088\right)$ in both sexes (Figure 2a). PPI of the startle response was reduced in female $\mathrm{CRFOE}_{\text {dev }}$ mice $\left(\mathrm{F}_{\text {sex } x \text { crfoe }}(1,50)=5.04, p=0.029\right.$; females: $\mathrm{F}_{\text {crfoe }}(1,24)=8.20$, $p=0.009$; males: $F_{\text {crfoe }}(1,26)<1$, ns) and was also reduced in 

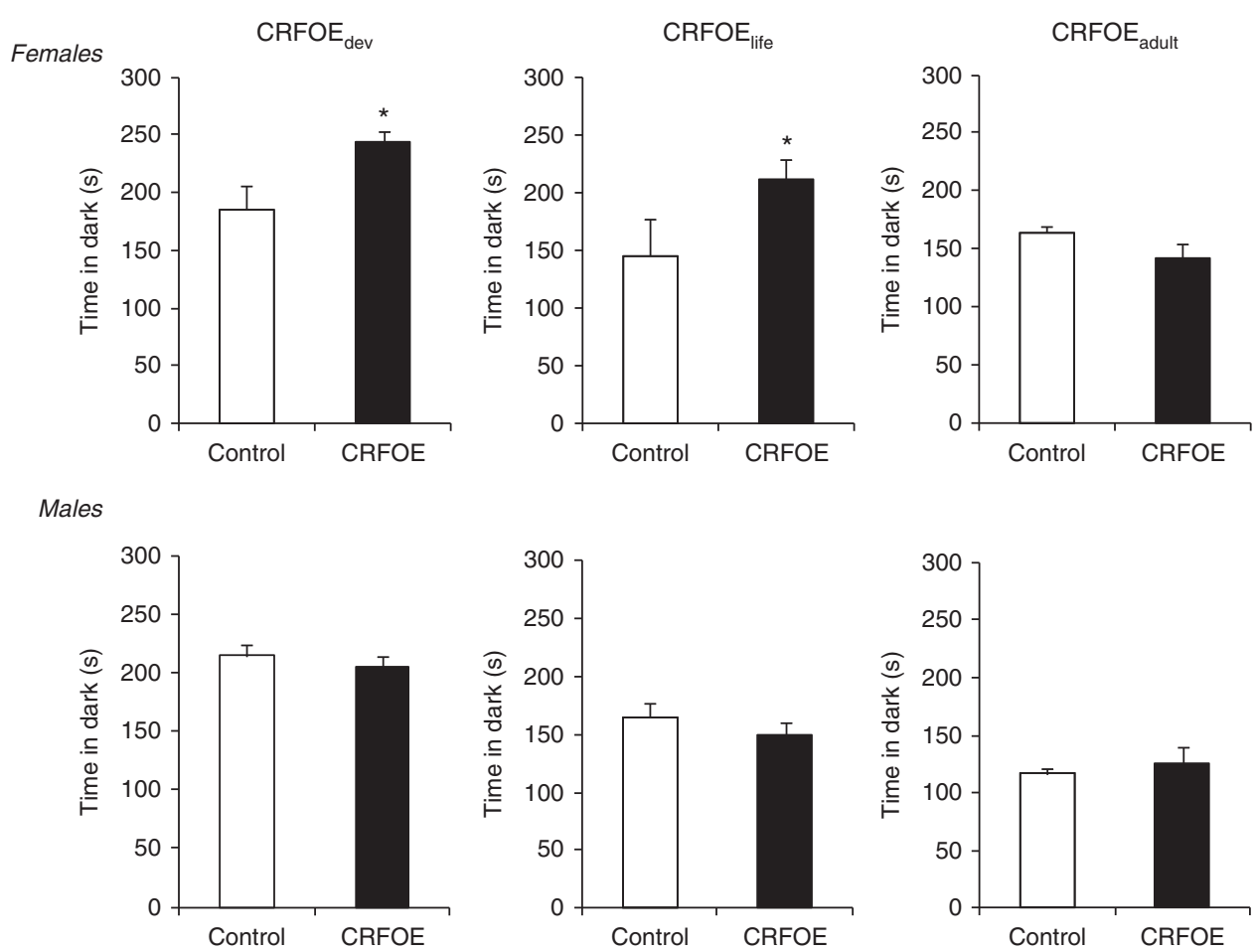

Figure 3 Avoidance behavior in the light-dark box following CRFOE $E_{\text {dev }}, C$ RFOE $E_{\text {life, }}$ and $C R F O E_{\text {adult. }}$ CRFOE $E_{\text {dev }}$ and $C R F O E_{\text {life }}$ but not $C R F O E_{\text {adult }}$ increased avoidance in female mice as indicated by the time spent in the dark compartment. Avoidance behavior in male subjects was not affected by CRFOE. $* p<0.05$ compared to same-sex control. Data are presented as mean \pm SEM.

$\mathrm{CRFOE}_{\text {life }}$ mice of both sexes $\left(\mathrm{F}_{\text {crfoe }}(1,39)=6.10, p=0.018\right.$; ns sex effect) (Figure 2b). Magnitude of startle alone during the PPI block was unaffected by CRFOE $\left(\mathrm{F}_{\text {crfoe }}<1.25\right.$, ns). In contrast, $\mathrm{CRFOE}_{\text {adult }}$ mice did not exhibit CRFOE effects on startle habituation and PPI $\left(\mathrm{F}_{\text {crfoe }}(1,39)<1, \mathrm{~ns} ; \mathrm{F}_{\text {crfoe }}\right.$ $(1,39)=1.33$, ns, respectively). However, male but not female $\mathrm{CRFOE}_{\text {adult }}$ mice exhibited increased startle magnitude $\left(\mathrm{F}_{\text {crfoe }}(1,18)=5.19, p=0.035 ; \mathrm{F}_{\text {crfoe }}(1,21)<1\right.$, ns, respectively $)$ (Supplementary Figure S2).

\section{Light/Dark Box Avoidance Test}

Female $\mathrm{CRFOE}_{\mathrm{dev}}$ and $\mathrm{CRFOE}_{\text {life }}$ mice exhibited increased avoidance as indexed by the time spent in the dark compartment $\quad\left(\mathrm{CRFOE}_{\mathrm{dev}}: \quad \mathrm{F}_{\text {crfoe }}(1,43)=4.65, \quad p=0.037\right.$; $\mathrm{F}_{\text {sex } \mathrm{x} \text { crfoe }}(1,43)=2.76, p=0.103$; Fisher's post hoc test for females: $p=0.013$ and males: $p=0.713$; $\operatorname{CRFOE}_{\text {life }}: \mathrm{F}_{\text {crfoe }}(1,38)$ $=2.22$, ns; $\mathrm{F}_{\text {sex x crfoe }}(1,38)=5.91, p=0.020$; Fisher's post hoc test for females: $p=0.019$ and males: $p=0.437$ ) (Figure 3 ). In contrast, $\mathrm{CRFOE}_{\text {adult }}$ mice did not exhibit differences in avoidance $\left(\mathrm{F}_{\text {crfoe }}(1,41)<1\right.$, ns). Entries to the light compartment did not depend on $\mathrm{CRFOE}_{\mathrm{dev}}, \mathrm{CRFOE}_{\text {life }}$ or $\mathrm{CRFOE}_{\mathrm{adult}}$ exposure, suggesting locomotor activity in the chamber was unaffected by CRFOE $\left(\mathrm{F}_{\text {crfoe }}<1, \mathrm{~ns}\right)$.

\section{DISCUSSION}

Here we directly compared CRFOE in the forebrain during selective periods of the lifespan to model different possible CRF hypersignaling events on anxiety-like traits. We showed that CRFOE during prepubertal development, particularly in females, produced the strongest effects on anxiety-like behaviors with increased avoidance, diminished startle habituation and reduced PPI. Lifetime CRFOE induced similar behavioral trends suggesting that the impact of CRFOE in this group was mainly exerted during development, and hence, CRF hypersignaling during early life has enduring consequences on these anxiety-like traits. In contrast, CRFOE limited to adulthood had relatively mild and differential effects on anxiety-related phenotypes suggesting that anxiety-related phenotypic changes could depend on the timing of CRF hypersignaling across the lifespan. On the basis of these findings, developmental CRFOE may model some of the enduring anxiogenic effects of early-life stress, and have a significant role in heightened stress vulnerability in females.

Although we found convergences between the phenotypic changes induced by $\mathrm{CRFOE}_{\mathrm{dev}}$ and $\mathrm{CRFOE}_{\text {life, which are }}$ consistent with previous CRFOE models, our immunohistochemical analysis revealed marked differences of CRF-ir patterns between these models at the time of behavioral testing (PD90). $\mathrm{CRFOE}_{\mathrm{dev}}$ resulted in small increases in CRF levels predominantly in brain regions that endogenously express significant CRF and mediates anxiogenic effects of CRF (ie, extended amygdala) (Plotsky et al, 2005; Rainnie et al, 2004; Regev et al, 2012). This expression profile is similar to expression profiles in mice with CRFOE controlled by the metallothionein promoter, with the exception of hypothalamic overexpression (Figure 1a, Table 1 (Stenzel-Poore et al, 1994)). In contrast, CRFOE life $_{\text {en }}$ and $\mathrm{CRFOE}_{\text {adult }}$ expression profile showed relatively normal CRF-ir labeling in the extended amygdala but strong labeling in the striatum and hippocampus, which have 
Table 2 Summary of Phenotypic Changes in Anxiety-Related Symptom Domains Following CRFOE $\mathrm{dev}_{\text {dev }} \mathrm{CRFOE}_{\mathrm{life}}$, and $\mathrm{CRFOE}_{\text {adult }}$

\begin{tabular}{|c|c|c|c|c|c|c|}
\hline \multirow[t]{2}{*}{ Behavior } & \multicolumn{2}{|c|}{ CRFOE $_{\mathrm{dev}}$} & \multicolumn{2}{|c|}{ CRFOE $_{\text {life }}$} & \multicolumn{2}{|c|}{ CRFOE $_{\text {adult }}$} \\
\hline & Females & Males & Females & Males & Females & Males \\
\hline Conditioned fear & - & - & - & - & $\downarrow$ & - \\
\hline Avoidance & $\uparrow$ & - & $\uparrow$ & - & - & - \\
\hline Startle magnitude & - & - & - & - & - & $\uparrow$ \\
\hline Startle habituation & $\downarrow$ & $\downarrow$ & $(\downarrow)$ & $(\downarrow)$ & - & - \\
\hline Prepulse inhibition & $\downarrow$ & - & $\downarrow$ & $\downarrow$ & - & - \\
\hline Locomotor activity & $(\uparrow)$ & - & - & $(\downarrow)$ & $(\uparrow)$ & - \\
\hline
\end{tabular}

- no effect; $\uparrow / \downarrow$ significant $(p<0.05)$ increase/decrease; $(\uparrow) /(\downarrow)$ marginal $(p<0.10)$ increase/decrease.

lower CRF levels endogenously (Swanson et al, 1983). Interestingly, CRF was recently found to exert anxiolytic actions in the globus pallidus and midbrain dopaminergic neurons in contrast to its major anxiogenic effects in the forebrain (Muller et al, 2003; Refojo et al, 2011; Sztainberg et al, 2011). Lifetime CRFOE was also reported to induce significant CRF receptor expression changes in several forebrain areas including the cortex, septum, globus pallidus, and substantia nigra with additional reduction of urocortin expression (Korosi et al, 2006; Kozicz et al, 2004). These findings may partially explain the different phenotypes between the $\mathrm{CRFOE}_{\text {dev }}, \mathrm{CRFOE}_{\text {life }}$, and $\mathrm{CRFOE}_{\text {adult }}$ exposure models, with striatal CRF signaling possibly competing with the anxiogenic effects of CRF in other limbic regions. Since the present study focuses on the temporal comparison of CRFOE and lacks cell-type and region-specific manipulations of CRF expression, future studies are necessary to clarify this question. Importantly, during DOX administration period (PD2-23), we found that CRFOE $_{\text {dev }}$ mice showed a regional profile of CRFOE that mimicked $\mathrm{CRFOE}_{\text {life }}$ and $\mathrm{CRFOE}_{\text {adult }}$ groups at PD90, ie, high CRFOE in cortex, hippocampus, and striatum (Figure 1b). These data suggest that CRFOE was relatively uniform in distribution across these different exposure models during active DOX treatment. The similar behavioral consequences of $\mathrm{CRFOE}_{\text {dev }}$ and $\mathrm{CRFOE}_{\text {life }}$ that appear to be independent of acute CRF peptide levels at the time of testing suggest that increased avoidance and startle reactivity were due to developmental changes induced by early-life CRFOE.

Although the anxiogenic effects of acute CRF activation is well-documented (Adamec et al, 2010; Baldwin et al, 1991), the present study with other CRFOE models can help to understand the specific spatio-temporal mechanisms of CRF in the development of heightened anxiety. First, CRFOE increased anxiety-like traits without affecting basal corticosterone concentrations, suggesting that CRF can exert anxiogenic effects independently from HPA-axis activation. These data are in line with other studies showing CRFR1 effects on anxiety that are independent of corticosterone or HPA CRF1 signaling (Muller et al, 2003; Smith et al, 1998; Timpl et al, 1998). Second, these findings support the importance of early-life CRF hypersignaling in the development of heightened anxiety-like traits by showing increased anxiety in mice exposed to developmental CRFOE but not in mice exposed to adult-onset CRFOE. Consistently, embryonic-developmental (embryonic day 0 to PD21) or lifetime but not adult forebrainspecific CRFOE increased avoidance in most previous CRFOE models (Kolber et al, 2010; Stenzel-Poore et al, 1994; Vicentini et al, 2009), but see (Groenink et al, 2003). Several developmental studies have reported significant alterations in CRF activity in the forebrain following maternal separation and low maternal care as well as elevated CRF levels in the cerebrospinal fluid in these animals (Coplan et al, 1996; Ladd et al, 1996; Plotsky et al, 2005). This latter finding is in line with human reports showing association between elevated cerebrospinal CRF concentration and childhood trauma history (Carpenter et al, 2004; Lee et al, 2005). In addition, the CRF system shows intense maturation during early postnatal periods, eg, significant changes in CRFR1/R2 receptor expression (Avishai-Eliner et al, 1996), thus early-life stress and CRF activation during this period can result in significant morphological and physiological changes in brain regions involved in stress-related behaviors (Ivy et al, 2010; Plotsky et al, 2005). These findings may explain some potential mechanisms how early-life stress induces enduring changes in anxiety and psychological vulnerability (Kessler et al, 2010).

CRFOE produced differential effects on startle reactivity by reducing habituation and PPI in mice exposed to developmental but not adult-onset overexpression. Only, male mice with adult-onset CRFOE exhibited increased startle magnitude which is consistent with acute CRF treatment effects (Risbrough et al, 2003). These findings suggest that exposure of the developing brain to CRF hypersignaling leads to marked changes of startle plasticity and sensorimotor gating. In humans, there is only indirect evidence for an association between PPI disruption and early-life stress, with some anxiety disorders with poor startle habituation and PPI deficits also being associated with early-life stressors (Braff et al, 2001; Ludewig et al, 2005). Future clinical research is needed to confirm if early-life stress is specifically associated with poor sensorimotor gating. Mechanisms for the developmental effect of CRFOE on PPI are currently unclear, however, lifetime CRFOE mice showed recovery of PPI after acute CRFR1 receptor antagonist treatments, inferring that the PPI deficits are due to CRFR1 hypersignaling (Groenink et al, 2008). Interestingly, the impact of CRFOE on fear conditioning revealed an opposite effect of exposure period on behavior compared to startle behaviors. Although acute CRF administration has been shown to enhance fear acquisition (Hubbard et al, 2007; Radulovic et al, 1999), adult-onset CRFOE reduced context-dependent freezing in females but left conditioned fear unaffected following prepubertal or lifetime exposure. Previous models of lifetime CRFOE similarly showed either no effect or reduced conditioned fear learning (Groenink et al, 2003). Thus chronic CRF hypersignaling in adulthood affects contextual freezing differently than acute manipulations, suggesting neuroadaption in CRF signaling pathways that affect learned fear (Silberstein et al, 2009). 
Most of the observed behavioral effects of CRFOE were present or more pronounced in females (for a summary, see Table 2). Given the very robust overexpression of the transgene (Figure 1a and $\mathrm{b}$ ), we do not expect that the behavioral sex differences are due to differences in expression of the CRF transgene itself, but are instead due to sex differences in the endogenous CRF signaling pathways in response to high CRF since females exhibit altered cellular responses to CRF signaling (Bangasser et al, 2013). Locus coeruleus neurons of female rats are more sensitive to CRF resulting in heightened noradrenergic reactivity during stress or in conditions of CRF overexpression, likely due to their limited ability to desensitize CRFR1 receptors (Bangasser et al, 2010; Bangasser et al, 2013; Curtis et al, 2006). This mechanism may partly explain why women show higher incidence of stress-related affective and anxiety disorders compared to men and why CRFOE appeared to result in more behavioral changes in females compared to males (Koenen and Widom, 2009).

There are a number of limitations to this study that should be noted. The forebrain CRFOE pattern that was induced by the CAMK2a promoter induced ectopic CRF expression in areas with relatively low CRF receptor abundance (eg, striatum). The phenotypes were relatively similar across $\mathrm{CRFOE}_{\mathrm{dev}}$ and $\mathrm{CRFOE}_{\text {life, }}$ despite relatively large differences in peptide distribution and level at the time of testing, which may suggest that the behavioral effects were driven by CRF signaling in a limited shared circuit. In addition, we cannot exclude the possibility that the differences in phenotype between adult exposure and the other groups could be at least partially accounted for differences in delays between behavioral testing and induction of CRFOE. Further study is warranted to examine if these behavioral phenotypes are altered across differential time periods after CRFOE is initiated and to identify when, after development, the effects of prepubertal CRFOE emerge. Overall, the present study provides evidence for a causal role of early-life CRF hypersignaling in the development of specific 'symptom domains' related to anxiety disorders in adulthood. The fact that forebrain CRFOE during early development could account for all of the effects of CRFOE across the lifespan suggests that forebrain CRFOE in development has relatively strong consequences on adult anxiety-like traits. Finally, the overall finding that females were more responsive to CRFOE across the different exposure groups supports the hypothesis that females may exhibit differential sensitivity to CRF signaling compared to males.

\section{FUNDING AND DISCLOSURE}

These studies were supported by Grants NIMH R074697 for VR, MH040008 for RJV, MH092438 for DAB, T32 MH18399 for EIF, NARSAD Young Investigator Award for JEG, and the San Diego Veterans Administration Center of Excellence for Stress and Mental Health. Drs Toth, Gresack, Bangasser, Plona, Valentino, Flandreau, and Mansuy have no potential financial conflicts to report. Dr Risbrough also had research support from Sunovion, Janssen, Pfizer, and Omeros. EMP was a full-time employee of GlaxoSmithKline SPA, Italy, until December 2011; and since 2012, he has been a full-time employee of F Hoffmann-La Roche, Basel. In the past 3 years, Dr Geyer has received consulting compensation from Abbott, Acadia, Addex, Cerca, Dart, Lundbeck/Otsuka, Merck, Neurocrine, Omeros, Takeda, and Teva, and holds an equity interest in San Diego Instruments. Dr Geyer also has research grant support from Intracellular Therapeutics, Johnson \& Johnson, NIDA, NIMH, and the U.S. Veteran's Administration VISN 22 Mental Illness Research, Education, and Clinical Center.

\section{ACKNOWLEDGEMENTS}

We would like to thank Drs Richard Hauger and Susan Powell for comments and Alan Turken, Ton Steen, and Maya Gross for their technical assistance.

\section{REFERENCES}

Adamec R, Fougere D, Risbrough V (2010). CRF receptor blockade prevents initiation and consolidation of stress effects on affect in the predator stress model of PTSD. Int J Neuropsychopharmacol 13: 747-757.

Avishai-Eliner S, Yi SJ, Baram TZ (1996). Developmental profile of messenger RNA for the corticotropin-releasing hormone receptor in the rat limbic system. Brain Res Dev Brain Res 91: 159-163.

Baker DG, West SA, Nicholson WE, Ekhator NN, Kasckow JW, Hill KK et al (1999). Serial CSF corticotropin-releasing hormone levels and adrenocortical activity in combat veterans with posttraumatic stress disorder. Am J Psychiatry 156: 585-588.

Baldwin HA, Rassnick S, Rivier J, Koob GF, Britton KT (1991). CRF antagonist reverses the "anxiogenic" response to ethanol withdrawal in the rat. Psychopharmacology 103: 227-232.

Bangasser DA, Curtis A, Reyes BA, Bethea TT, Parastatidis I, Ischiropoulos $\mathrm{H}$ et al (2010). Sex differences in corticotropinreleasing factor receptor signaling and trafficking: potential role in female vulnerability to stress-related psychopathology. Mol Psychiatry 15: 877, 896-904.

Bangasser DA, Reyes BA, Piel D, Garachh V, Zhang XY, Plona ZM et al (2013). Increased vulnerability of the brain norepinephrine system of females to corticotropin-releasing factor overexpression. Mol Psychiatry 18: 166-173.

Bradley RG, Binder EB, Epstein MP, Tang Y, Nair HP, Liu W et al (2008). Influence of child abuse on adult depression: moderation by the corticotropin-releasing hormone receptor gene. Arch Gen Psychiatry 65: 190-200.

Braff DL, Geyer MA, Swerdlow NR (2001). Human studies of prepulse inhibition of startle: normal subjects, patient groups, and pharmacological studies. Psychopharmacology 156: 234-258.

Bremner JD, Licinio J, Darnell A, Krystal JH, Owens MJ, Southwick SM et al (1997). Elevated CSF corticotropin-releasing factor concentrations in posttraumatic stress disorder. Am J Psychiatry 154: 624-629.

Carpenter LL, Tyrka AR, McDougle CJ, Malison RT, Owens MJ, Nemeroff CB et al (2004). Cerebrospinal fluid corticotropinreleasing factor and perceived early-life stress in depressed patients and healthy control subjects. Neuropsychopharmacology 29: 777-784.

Coplan JD, Andrews MW, Rosenblum LA, Owens MJ, Friedman S, Gorman JM et al (1996). Persistent elevations of cerebrospinal fluid concentrations of corticotropin-releasing factor in adult nonhuman primates exposed to early-life stressors: implications for the pathophysiology of mood and anxiety disorders. Proc Natl Acad Sci USA 93: 1619-1623. 
Curtis AL, Bethea T, Valentino RJ (2006). Sexually dimorphic responses of the brain norepinephrine system to stress and corticotropin-releasing factor. Neuropsychopharmacology 31: 544-554.

Flandreau EI, Ressler KJ, Owens MJ, Nemeroff CB (2012). Chronic overexpression of corticotropin-releasing factor from the central amygdala produces HPA axis hyperactivity and behavioral anxiety associated with gene-expression changes in the hippocampus and paraventricular nucleus of the hypothalamus. Psychoneuroendocrinology 37: 27-38.

Gresack JE, Risbrough VB, Scott CN, Coste S, Stenzel-Poore M, Geyer MA et al (2010). Isolation rearing-induced deficits in contextual fear learning do not require CRF(2) receptors. Behav Brain Res 209: 80-84.

Groenink L, Dirks A, Verdouw PM, de Graaff M, Peeters BW, Millan MJ et al (2008). CRF1 not glucocorticoid receptors mediate prepulse inhibition deficits in mice overexpressing CRF. Biol Psychiatry 63: 360-368.

Groenink L, Pattij T, De Jongh R, Van der Gugten J, Oosting RS, Dirks A et al (2003). 5-HT1A receptor knockout mice and mice overexpressing corticotropin-releasing hormone in models of anxiety. Eur J Pharmacol 463: 185-197.

Heim C, Nemeroff CB (2001). The role of childhood trauma in the neurobiology of mood and anxiety disorders: preclinical and clinical studies. Biol Psychiatry 49: 1023-1039.

Hubbard DT, Nakashima BR, Lee I, Takahashi LK (2007). Activation of basolateral amygdala corticotropin-releasing factor 1 receptors modulates the consolidation of contextual fear. Neuroscience 150: 818-828.

Ivy AS, Rex CS, Chen Y, Dube C, Maras PM, Grigoriadis DE et al (2010). Hippocampal dysfunction and cognitive impairments provoked by chronic early-life stress involve excessive activation of CRH receptors. J Neurosci 30: 13005-13015.

Kessler RC, McGonagle KA, Swartz M, Blazer DG, Nelson CB (1993). Sex and depression in the National Comorbidity Survey. I: lifetime prevalence, chronicity and recurrence. J Affect Disord 29: 85-96.

Kessler RC, McLaughlin KA, Green JG, Gruber MJ, Sampson NA, Zaslavsky AM et al (2010). Childhood adversities and adult psychopathology in the WHO World Mental Health Surveys. $\mathrm{Br} \mathrm{J}$ Psychiatry 197: 378-385.

Koenen KC, Widom CS (2009). A prospective study of sex differences in the lifetime risk of posttraumatic stress disorder among abused and neglected children grown up. J Trauma Stress 22: 566-574.

Kolber BJ, Boyle MP, Wieczorek L, Kelley CL, Onwuzurike CC, Nettles SA et al (2010). Transient early-life forebrain corticotropin-releasing hormone elevation causes long-lasting anxiogenic and despair-like changes in mice. J Neuroscience 30: 2571-2581.

Korosi A, Veening JG, Kozicz T, Henckens M, Dederen J, Groenink $\mathrm{L}$ et al (2006). Distribution and expression of CRF receptor 1 and 2 mRNAs in the CRF over-expressing mouse brain. Brain Res 1072: 46-54.

Kozicz T, Korosi A, Korsman C, Tilburg-Ouwens D, Groenink L, Veening $\mathrm{J}$ et al (2004). Urocortin expression in the EdingerWestphal nucleus is down-regulated in transgenic mice overexpressing neuronal corticotropin-releasing factor. Neuroscience 123: $589-594$.

Ladd CO, Owens MJ, Nemeroff CB (1996). Persistent changes in corticotropin-releasing factor neuronal systems induced by maternal deprivation. Endocrinology 137: 1212-1218.

Lee R, Geracioti TD Jr., Kasckow JW, Coccaro EF (2005). Childhood trauma and personality disorder: positive correlation with adult CSF corticotropin-releasing factor concentrations. Am J Psychiatry 162: 995-997.

Ludewig S, Geyer MA, Ramseier M, Vollenweider FX, Rechsteiner E, Cattapan-Ludewig K (2005). Information-processing deficits and cognitive dysfunction in panic disorder. J Psychiatry Neurosci 30: 37-43.

Michalon A, Koshibu K, Baumgartel K, Spirig DH, Mansuy IM (2005). Inducible and neuron-specific gene expression in the adult mouse brain with the rtTA2S-M2 system. Genesis 43: 205-212.

Muller MB, Zimmermann S, Sillaber I, Hagemeyer TP, Deussing JM, Timpl P et al (2003). Limbic corticotropin-releasing hormone receptor 1 mediates anxiety-related behavior and hormonal adaptation to stress. Nat Neurosci 6: 1100-1107.

Paxinos G, Franklin KBJ (2004). The Mouse Brain in Stereotaxic Coordinates. compact 2nd edn. Academic Press: San Diego, Calif.; London, xxxi 100 pof platespp.

Plotsky PM, Thrivikraman KV, Nemeroff CB, Caldji C, Sharma S, Meaney MJ (2005). Long-term consequences of neonatal rearing on central corticotropin-releasing factor systems in adult male rat offspring. Neuropsychopharmacology 30: 2192-2204.

Radulovic J, Ruhmann A, Liepold T, Spiess J (1999). Modulation of learning and anxiety by corticotropin-releasing factor (CRF) and stress: differential roles of CRF receptors 1 and 2. J Neurosci 19: 5016-5025.

Rainnie DG, Bergeron R, Sajdyk TJ, Patil M, Gehlert DR, Shekhar A (2004). Corticotrophin releasing factor-induced synaptic plasticity in the amygdala translates stress into emotional disorders. J Neurosci 24: 3471-3479.

Refojo D, Schweizer M, Kuehne C, Ehrenberg S, Thoeringer C, Vogl AM et al (2011). Glutamatergic and dopaminergic neurons mediate anxiogenic and anxiolytic effects of CRHR1. Science 333: 1903-1907.

Regev L, Tsoory M, Gil S, Chen A (2012). Site-specific genetic manipulation of amygdala corticotropin-releasing factor reveals its imperative role in mediating behavioral response to challenge. Biol Psychiatry 71: 317-326.

Risbrough VB, Hauger RL, Pelleymounter MA, Geyer MA (2003). Role of corticotropin releasing factor (CRF) receptors 1 and 2 in CRF-potentiated acoustic startle in mice. Psychopharmacology 170: $178-187$.

Risbrough VB, Hauger RL, Roberts AL, Vale WW, Geyer MA (2004). Corticotropin-releasing factor receptors CRF1 and CRF2 exert both additive and opposing influences on defensive startle behavior. J Neurosci 24: 6545-6552.

Risbrough VB, Masten VL, Caldwell S, Paulus MP, Low MJ, Geyer MA (2006a). Differential contributions of dopamine D1, D2, and D3 receptors to MDMA-induced effects on locomotor behavior patterns in mice. Neuropsychopharmacology 31: 2349-2358.

Risbrough VB, Stein MB (2006b). Role of corticotropin releasing factor in anxiety disorders: a translational research perspective. Horm Behav 50: 550-561.

Silberstein S, Vogl AM, Refojo D, Senin SA, Wurst W, Holsboer F et al (2009). Amygdaloid pERK1/2 in corticotropin-releasing hormone overexpressing mice under basal and acute stress conditions. Neuroscience 159: 610-617.

Smith GW, Aubry JM, Dellu F, Contarino A, Bilezikjian LM, Gold LH et al (1998). Corticotropin releasing factor receptor 1deficient mice display decreased anxiety, impaired stress response, and aberrant neuroendocrine development. Neuron 20: 1093-1102.

Stenzel-Poore MP, Heinrichs SC, Rivest S, Koob GF, Vale WW (1994). Overproduction of corticotropin-releasing factor in transgenic mice: a genetic model of anxiogenic behavior. $J$ Neurosci 14(5 Pt 1): 2579-2584.

Swanson LW, Sawchenko PE, Rivier J, Vale WW (1983). Organization of ovine corticotropin-releasing factor immunoreactive cells and fibers in the rat brain: an immunohistochemical study. Neuroendocrinology 36: 165-186.

Sztainberg Y, Kuperman Y, Justice N, Chen A (2011). An anxiolytic role for CRF receptor type 1 in the globus pallidus. J Neurosci 31: 17416-17424. 
Timpl P, Spanagel R, Sillaber I, Kresse A, Reul JM, Stalla GK et al (1998). Impaired stress response and reduced anxiety in mice lacking a functional corticotropin-releasing hormone receptor 1 . Nat Genet 19: 162-166.

Vicentini E, Arban R, Angelici O, Maraia G, Perico M, Mugnaini M et al (2009). Transient forebrain over-expression of CRF induces plasma corticosterone and mild behavioural changes in adult conditional CRF transgenic mice. Pharmacol Biochem Behav 93: $17-24$.

Weathington JM, Cooke BM (2012). Corticotropin-releasing factor receptor binding in the amygdala changes across puberty in a sex-specific manner. Endocrinology 153: 5701-5705.

Zorrilla EP, Koob GF (2010). Progress in corticotropin-releasing factor-1 antagonist development. Drug Discov Today 15: 371-383.

Supplementary Information accompanies the paper on the Neuropsychopharmacology website (http://www.nature.com/npp) 